\title{
Formulation, characterization and evaluation of the effect of polymer concentration on the release behavior of insulin-loaded Eudragit ${ }^{\circledast}$-entrapped mucoadhesive microspheres
}

\author{
Franklin C. Kenechukwu, Mumuni A. Momoh \\ Drug Delivery and Nanomedicines Research Unit, Department of Pharmaceutics, University of Nigeria, Nsukka, Enugu State, Nigeria
}

\begin{abstract}
Introduction: The aim of this study was to use Eudragit ${ }^{\circ} \mathrm{RL} 100$ (pH-independent polymer) and magnesium stearate (a hydrophobic droplet stabilizer) in combination to improve the controlled release effect of insulin-loaded Eudragit entrapped microspheres prepared by the emulsification-coacervation technique. Materials and Methods: Mucoadhesive insulin-loaded microspheres containing magnesium stearate and varying proportions of Eudragit ${ }^{\circ} \mathrm{RL} 100$ were prepared by the emulsification-coacervation technique and evaluated for thermal properties, physicochemical performance, and in vitro dissolution in acidic and subsequently basic media. Results: Stable, spherical, brownish, discrete, freeflowing and mucoadhesive insulin-loaded microspheres with size range of $14.20 \pm 0.30-19.80 \pm 0.60 \mu \mathrm{m}$ and loading efficiency of $74.55 \pm 1.05-75.90 \pm 1.94 \%$ were formed. After $3 \mathrm{~h}$, microspheres prepared with insulin: Eudragit $^{\circ} \mathrm{RL} 100$ ratios of $1: 4,1: 6$, and $1: 8$ released $73.40 \pm 1.38,66.20 \pm 1.59$, and $71.30 \pm 1.27(\%)$ of insulin, respectively. Conclusion: The physicochemical and physico-technical properties of the microspheres developed in this study demonstrated the effectiveness of the Eudragit ${ }^{\oplus} \mathrm{RL}$ entrapped mucoadhesive microspheres (prepared by the emulsification-coacervation technique using varying polymer concentration) as a carrier system for oral insulin delivery.
\end{abstract}

Key words: Eudragit ${ }^{\mathbb{R}}$ RL 100, insulin release, microspheres, percentage mucoadhesion

\section{INTRODUCTION}

Insulin is a macromolecule with a molecular weight of $5,808 \mathrm{~g} / \mathrm{mol}$ in humans and it contains 51 amino acids arranged in two chains (A and B) linked by disulfide bridges. ${ }^{[1]}$ The administration of insulin to diabetic patients is mainly via subcutaneous injection. However, there are limitations or problems encountered during subcutaneous insulin injection including local discomfort, pain, allergic reactions, hyperinsulinemia as well as inconvenience of multiple injections and occasional hypoglycemia as a result of overdose. ${ }^{[2-4]}$ Because

\section{Address for correspondence:}

Dr. Franklin C. Kenechukwu,

Department of Pharmaceutics, University of Nigeria,

Nsukka - 410001, Enugu State, Nigeria.

E-mail: frankline.kenechukwu@unn.edu.ng

\begin{tabular}{|l|l|}
\hline \multicolumn{2}{|c|}{ Access this article online } \\
\hline Quick Response Code: & Website: \\
\hline & www.jpionline.org \\
\cline { 2 - 2 } & DOI: \\
\hline
\end{tabular}

of these problems, novel approaches for insulin delivery are being explored including oral, rectal, pulmonary, uterine, and ocular delivery as well as subcutaneous implants. Delivery options that use dermal, nasal, and transdermal approaches have also been explored, with current and more emphasis on the oral delivery system. ${ }^{[1,2,5-10]}$ The ease of administration and higher degree of patient compliance with oral dosage forms are the major reasons for preferring to deliver proteins and peptides such as insulin by mouth. In addition, administration of insulin via the oral route helps in eliminating the pain caused by injection and the psychological barriers linked with multiple daily injections such as needle anxiety and possible infections. ${ }^{[11,12]}$

This is an open access article distributed under the terms of the Creative Commons Attribution-NonCommercial-ShareAlike 3.0 License, which allows others to remix, tweak, and build upon the work non-commercially, as long as the author is credited and the new creations are licensed under the identical terms.

For reprints contact: reprints@medknow.com

How to cite this article: Kenechukwu FC, Momoh MA. Formulation, characterization and evaluation of the effect of polymer concentration on the release behavior of insulin-loaded Eudragit ${ }^{\circledR}$-entrapped mucoadhesive microspheres. Int J Pharma Investig 2016;6:69-77. 
Attempts have been made to achieve oral insulin delivery using various systems. Researchers have prepared microparticles, liposomes, microemulsions, niosomes, and nanocubicles for the oral delivery of insulin. ${ }^{[13-18]}$ In terms of formulation strategies, microspheres as a dosage form provide benefits such as rapid emptying from the stomach as well as more reproducible transit through the small intestine and colon. Their increased surface area facilitates rapid drug release and more reproducible absorption than conventional dosage forms. ${ }^{[1,20]}$ Further advantages of microsphere drug delivery systems include effective protection of encapsulated drugs against degradation, increased drug solubility, reduced adverse or toxic effects, site-specific drug delivery, and controlled drug release. ${ }^{[21-23]}$

Microspheres are made up of natural and synthetic substances such as polymers or other natural polysaccharides such as starches and even waxes, gum, proteins and fats, and are used as drug carrier matrices for drug delivery. ${ }^{[24-27]}$ Microspheres have high efficacy for the absorption of a wide variety of lipophilic and hydrophilic substances. They aid in the protection of protein by preventing them from interacting with any substance till the complete degradation of the polymer and hence, reducing the contact with solutions, which degrade the protein. ${ }^{[28]}$ The choice of microencapsulation technique depends on the attributes of the polymers and the drug, the site of the drug action, and the duration of the therapy. ${ }^{[29-31]}$

Eudragits ${ }^{\circledR}$ are polymeric substances, the physicochemical properties of which are determined mainly by their functional groups. ${ }^{[32]}$ Eudragit ${ }^{\circledR}$ polymers are more favored in the formulation of $\mathrm{pH}$-sensitive drug molecules. The obvious advantages of these polymers include $\mathrm{pH}$-dependent release profiles, encapsulation of a high amount of drug, release of the incorporated drug in a controlled manner, and a high level of stability. ${ }^{[33]}$ Generally, Eudragits ${ }^{\circledR}$ are copolymers of acrylic and methacrylic acid esters with quaternary ammonium groups. The ammonium groups are present as salts and make the polymers permeable. ${ }^{[34]}$ Eudragit ${ }^{\circledR}$ $\mathrm{RL} 100$, which is $\mathrm{pH}$-independent and mainly releases its drug content in the intestine, was used for this research. Eudragit ${ }^{\circledR}$ RL 100 is a copolymer of acrylate and methacrylate with the quaternary ammonium group. It is totally esterified with no free carboxylic acid group, is neutral in character and insoluble in the entire physiological $\mathrm{pH}$ range. Since it is an amine salt, it is a typical ionic compound and so can be dissolved in water appreciably. Variation in the quantity of quaternary ammonium group causes variation in its permeability characteristics, ${ }^{[35]}$ which could be utilized to improve the impermeability characteristics of poorly permeable biomolecules such as insulin.

Consequently, the purpose of this research was to formulate and evaluate insulin-loaded microspheres using a copolymerEudragit ${ }^{\circledR}$ RL100 in order to overcome the barriers of administering insulin orally and to achieve a controlled release of the drug. Liquid paraffin and acetone were used for the preparation of the microspheres. Magnesium stearate was used as a droplet stabilizer to prevent droplet coalescence in the oil medium and n-hexane was added as a nonsolvent to the processing medium to solidify the microspheres. The effect of formulation factors such as polymer ratio of the microspheres was investigated. The prepared microspheres were evaluated for production yield, drug encapsulation, morphology, particle size, thermal, mucoadhesive and micromeritic properties, and in vitro drug release. To the best of our knowledge, this is the first microsphere delivery system comprising Eudragit ${ }^{\circledR}$ RL100 that has been tested for enhanced insulin delivery. Oral delivery of insulin using various carriers has been investigated by various researchers. ${ }^{[36-49]}$ The novelty of the work lies on the use of Eudragit ${ }^{\circledR}$ RL 100 and magnesium stearate (a hydrophobic droplet stabilizer) in combination to improve the controlled release effect of insulin-loaded Eudragit-entrapped microspheres prepared by the emulsification-coacervation technique. Emulsion-based formulations of insulin have been used to control the release of insulin. ${ }^{[50-54]}$ Emulsification enhances the fineness and droplet size of microspheres while magnesium stearate stabilizes the droplet sizes of microspheres. ${ }^{[55,56]}$

\section{MATERIALS AND METHODS}

\section{Materials}

The materials used include methacrylic acid copolymer (Eudragit ${ }^{\circledR}$ RL100; BASF Chemical Industry, Germany), sorbitan monostearate (Span 60; Merck, Germany), liquid paraffin (Moko Pharm. Ltd., Nigeria), magnesium stearate, n-hexane, acetonitrile and perchloric acid (BDH, England), potassium dihydrogen phosphate (monobasic potassium phosphate), sodium hydroxide, concentrated hydrochloric acid and acetone (Sigma-Aldrich, USA), distilled water (freshly prepared in Biochemistry lab, UNN), and insulin (Humulin 70/30; Lilly, Egypt). These materials were used as procured from the manufacturers without further purification. All other reagents were of an analytical grade and used as such.

\section{Formulation of insulin-loaded microspheres}

Insulin microspheres were prepared according to the oil-in-oil emulsification-coacervation method using Eudragit ${ }^{\circledR}$ RL100 polymer, which was dissolved in $12.5 \mathrm{~mL}$ of acetone in a $250 \mathrm{~mL}$ beaker with stirring at room temperature. Insulin $[0.5 \mathrm{~mL}$ of 100 international units (IU)] and magnesium stearate $(0.1 \mathrm{~g})$ were dispersed in the polymer solution. The resulting milky white dispersion was added drop-wise into a beaker containing a mixture of liquid paraffin $(50 \mathrm{~mL})$ and span 60 (0.5 g) and homogenized using a paddle stirrer (Remi Instruments, Mumbai, Maharashtra, India) at $500 \mathrm{rpm}$ for $2 \mathrm{~h}$. The resulting microspheres were harvested by filtration and washed severally with n-hexane until they were completely free of oil. The microspheres were dried at room temperature and stored at $4^{\circ} \mathrm{C}$ until used. Three batches of the microspheres were prepared for different amounts of the polymer and a control was also prepared using the above method without insulin, as shown below in Table 1. 


\section{Determination of percentage yield}

The formed microspheres were recovered and weighed accurately. The yield of microspheres was determined by comparing the whole weight of the formed microspheres against the combined weight of the copolymer and drug using the equation below:

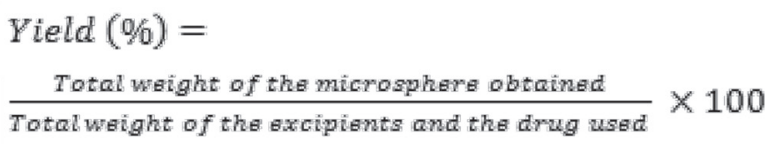

\section{Thermal analysis}

Briefly, the thermal properties of insulin, Eudragit ${ }^{\circledR}$ RL 100, and drug-loaded microspheres were studied using a differential scanning calorimeter (204 F1 Netzch, Germany) to evaluate any possible drug-polymer interaction. The analysis was performed at a heating rate of $10^{\circ} \mathrm{C} / \mathrm{min}$ in a temperature range of $10^{\circ} \mathrm{C}$ to $400^{\circ} \mathrm{C}$ under an inert nitrogen atmosphere with a flow rate of $20 \mathrm{~mL} / \mathrm{min}$.

\section{Quantitative determination of insulin}

The insulin content of the microspheres was determined using a high-performance liquid chromatography (HPLC). The machine consisted of an Agilent 1100 series programmable separating module, quatenary pump G 1311 A (Agilent technology, Geneva, Switzerland), an auto-degasser G1322A, and a variable wavelength detector G1314A. The column was a reverse phase ODS (C-18, $5 \mu \mathrm{m} 4.6 \times 250 \mathrm{~mm}$, Supercosol, USA) equipped with a guard. The mobile phase consisted of acetonitrile and water (10:90), perchloric acid was used to adjust the $\mathrm{pH}$ to 3. The flow was set at $0.8 \mathrm{~mL} / \mathrm{min}$ and the chromatograms were recorded at $280 \mathrm{~nm}$.

\section{Insulin-loading efficiency}

A $10 \mathrm{mg}$ quantity of microspheres was dispersed in $10 \mathrm{~mL}$ of simulated intestinal fluid (SIF, $\mathrm{pH}$ 7.2). The dispersion was allowed to stand for $2 \mathrm{~h}$ after which, it was mixed with a vortex mixer (Remi Instruments, Mumbai, Maharashtra, India) for $5 \mathrm{~min}$ and then centrifuged at 4,000 rpm for $10 \mathrm{~min}$. The amount of insulin contained in each batch of the formulations was determined by the HPLC method. The drug-loading efficiency was then determined by evaluating with equation $2 .^{[7]}$

$$
I L E=\frac{A D}{T D} \times 100
$$

\begin{tabular}{|c|c|c|c|c|}
\hline $\begin{array}{l}\text { Formulation } \\
\text { code }\end{array}$ & $\begin{array}{l}\text { Insulin (mL } \\
\text { of } 100 \mathrm{IU})\end{array}$ & $\begin{array}{l}\text { Eudragit }^{\circledR} \\
\text { RL } 100 \text { (g) }\end{array}$ & $\begin{array}{l}\text { Magnesium } \\
\text { stearate }(g)\end{array}$ & $\begin{array}{l}\text { Drug: } \\
\text { polymer } \\
\text { ratio }\end{array}$ \\
\hline$U_{0}$ & 0.0 & 2 & 0.1 & $0: 1$ \\
\hline $\mathrm{U}_{1}^{0}$ & 0.5 & 2 & 0.1 & $1: 4$ \\
\hline $\mathrm{U}_{2}^{1}$ & 0.5 & 3 & 0.1 & $1: 6$ \\
\hline $\mathrm{U}_{3}^{2}$ & 0.5 & 4 & 0.1 & $1: 8$ \\
\hline
\end{tabular}

where ILE is insulin-loading efficiency, AD is the actual amount of insulin in microspheres, and TD is the theoretical amount of insulin in microspheres.

\section{Morphology and particle size analysis}

The size and morphology of the microspheres were analyzed by computerized image analysis using samples mounted on a glass slide (Marinfield, Weltzlar, Hesse, Germany). These samples were dispersed in a little quantity of liquid paraffin and smeared on the slide using a glass rod. It was then covered with a cover slip and viewed with a photomicroscope (Hund ${ }^{\circledR}$, Weltzlar, Hesse, Germany) attached with a digital camera at a magnification of $1000 \mathrm{x}$. With the aid of the software in the photomicroscope, the particle morphologies were observed and photomicrographs were taken. The sizes of the particles were measured $(n=30)$ and the average was taken.

\section{Mucoadhesiveness of the microspheres}

The mucoadhesive properties of the microspheres were evaluated by the in vitro wash-off test as reported by Ofokansi and Adikwu. ${ }^{[57]}$ The apparatus used for this study was designed to give reproducible results. A 200-mg quantity of the microspheres was weighed accurately and placed on an $8.5-\mathrm{cm}$ long porcine ileum and allowed to interact with and adhere to the surface of the ileum. A 50-mL portion of simulated intestinal fluid (SIF) was poured into a separating funnel clamped to a retort stand and allowed to run over the microspheres on the porcine ileum. The microspheres that detached from the ileum were collected, dried, and weighed. This was repeated for all batches. The percentage mucoadhesion for each batch was calculated using the formula below:

\section{Percentage mucoadhesion $=$}

$$
\frac{\text { weight applied-weight detached }}{\text { weight applied }} \text { X } 100
$$

\section{Micromeritics properties of the microspheres}

The flow properties of the microspheres were investigated by measuring the bulk density, tapped density, Carr index, and Hausner ratio using standard methods. ${ }^{[26,30]}$

\section{In vitro release of insulin from the microspheres}

The in vitro release profiles of the insulin-loaded microspheres were determined in acidic and basic media. ${ }^{[58]} \mathrm{A} 100-\mathrm{mg}$ quantity of the insulin-loaded microspheres was filled into hard gelatin capsules. Each capsule was then placed in a $250-\mathrm{mL}$ beaker containing $150 \mathrm{~mL}$ of phosphate citrate buffer solution ( $\mathrm{pH} 2.2$ ); agitation of the fluid system $(100 \mathrm{rpm})$ was done with a magnetic stirrer (Remi Instruments, Mumbai, Maharashtra, India). At predetermined time intervals, 2-mL samples were withdrawn and replaced with phosphate citrate buffer solution. After $1 \mathrm{~h}$, the $\mathrm{pH}$ of the dissolution medium was changed to 7.2 by the addition of $0.1 \mathrm{~N}$ sodium hydroxide and further sampling was continued for another $3 \mathrm{~h}$. The temperature of the dissolution system and the 
Table 2: Some physicochemical and physico-technical properties of the microspheres

\begin{tabular}{|c|c|c|c|c|c|c|c|c|}
\hline Batch code & Yield (\%) & Size $(\mu \mathrm{m})^{\mathrm{a}, \mathrm{b}}$ & $E E(\%)^{a, b}$ & Muco- adhesion $(\%)^{\mathrm{a}, \mathrm{b}}$ & $\mathrm{BD}(\mathrm{g} / \mathrm{mL})^{\mathrm{a}, \mathrm{b}}$ & TD $(g / m L)^{a, b}$ & $H Q^{a, b}$ & $\mathrm{Cl}(\%)^{\mathrm{a}, \mathrm{b}}$ \\
\hline$U_{0}$ & 50.93 & $13.5 \pm 0.9$ & - & $75 \pm 2.3$ & $0.31 \pm 0.04$ & $0.42 \pm 0.03$ & $1.22 \pm 0.04$ & $15.27 \pm 1.90$ \\
\hline$U_{1}$ & 63.99 & $14.2 \pm 0.3$ & $75.23 \pm 2.10$ & $70 \pm 2.5$ & $0.29 \pm 0.02$ & $0.30 \pm 0.01$ & $1.04 \pm 0.07$ & $13.43 \pm 1.63$ \\
\hline $\mathrm{U}_{2}^{\prime}$ & 77.62 & $17.6 \pm 0.5$ & $75.90 \pm 1.94$ & $80 \pm 3.0$ & $0.39 \pm 0.01$ & $0.50 \pm 0.02$ & $1.24 \pm 0.03$ & $22.23 \pm 2.08$ \\
\hline $\mathrm{U}_{3}^{2}$ & 71.16 & $19.8 \pm 0.6$ & $74.55 \pm 1.05$ & $60 \pm 2.9$ & $0.44 \pm 0.01$ & $0.55 \pm 0.02$ & $1.23 \pm 0.05$ & $18.91 \pm 1.54$ \\
\hline
\end{tabular}

${ }^{a}$ Mean $\pm S D,{ }^{b} n=3, U_{1}, U_{2}$ and $U_{3}$ are insulin-loaded microspheres containing 2,3 and $4 \mathrm{~g}$ of Eudragit ${ }^{\oplus} R L$ 100 while $U_{0}$ is the unloaded microspheres, BD: Bulk density,

TD: Tapped density, HQ: Hausner's qoutient, Cl: Compressibilty index

replacement fluid were maintained at $37 \pm 0.5^{\circ} \mathrm{C}$. The insulin content of the withdrawn samples was determined using the HPLC quantitative method and the release profiles plotted.

\section{Kinetic analysis of in vitro release profiles}

The dissolution data for the microspheres were analyzed to determine the in vitro release kinetic models and mechanisms. Four kinetic models including the zero-order, first-order, Higuchi square root, and Hixson-Crowell cube root models were applied to process the release data to find out the equation with the best fit. ${ }^{[28,33]}$

$\mathrm{Q}=\mathrm{K}_{1} \mathrm{t}$

$\mathrm{Q}=100\left(1-\mathrm{e}^{-\mathrm{K}}{ }_{2}^{\mathrm{t}}\right)$

$\mathrm{Q}=\mathrm{K}_{3}(\mathrm{t}) 1 / 2$

$\mathrm{Q}=100^{\frac{1}{3} \mathrm{~K}_{4} \mathrm{t}}$

where $\mathrm{Q}$ is the release percentage at time, $t . \mathrm{K}_{1}, \mathrm{~K}_{2}, \mathrm{~K}_{3}$, and $\mathrm{K}_{4}$ are the rate constants of zero-order, first-order, Higuchi, and Hixson-Crowell models, respectively.

\section{Statistical analysis}

All experiments were performed in replicates for validity of statistical analysis. Results were expressed as mean \pm standard deviation (SD). Analysis of variance (ANOVA) and Student's $t$-test were performed on the data sets generated using Statistical Package for the Social Sciences (SPSS). The differences were considered significant for $P \leq 0.05$.

\section{RESULTS AND DISCUSSION}

The percentage yield of all the batches ranged from 50.93\% to $77.62 \%$, with batch $\mathrm{U}_{2}$ having the highest percentage yield [Table 2]. The yield of the microspheres was generally high. There was no evidence of correlation between the drug: polymer ratio used in the formulation of microspheres and the microspheres yield. In all cases, the yield of the microspheres from all the formulations were generally high indicating that the formulation procedures and parameters employed in formulating the microspheres are very effective and efficient. The percentage loss was low, and this might rise during the filtration, transferring, or drying.

Figure 1 shows the thermograms of insulin and the microspheres while Table 3 presents the thermal properties of insulin and the formulations. Differential scanning calorimetry (DSC) result of
Table 3: Thermal properties of the formulations

Formulation code $\quad$ Melting point $\left({ }^{\circ} \mathrm{C}\right) \quad$ Enthalpy $(\mathrm{mW} / \mathrm{mg})$

\begin{tabular}{lcc} 
Insulin & 125 & -132 \\
$\mathrm{U}_{0}$ & $62.7(78.2)$ & $-4.216(-4.131)$ \\
$\mathrm{U}_{1}$ & 63.6 & -4.777 \\
$\mathrm{U}_{2}^{2}$ & $64.2(85.6)$ & $-8.821(-7.662)$ \\
$\mathrm{U}_{3}$ & $63.9(81.6)$ & $-3.360(-2.561)$ \\
\hline
\end{tabular}

$\mathrm{U}_{1^{\prime}} \mathrm{U}_{2}$ and $\mathrm{U}_{3}$ are insulin-loaded microspheres containing $2 \mathrm{~g}, 3 \mathrm{~g}$, and $4 \mathrm{~g}$ of Eudragit ${ }^{\circ}$ $R L 100$ while $U_{0}$ is the unloaded microspheres

insulin showed a melting peak of $125^{\circ} \mathrm{C}$ with an enthalpy of $132 \mathrm{~mW} /$ $\mathrm{mg}$ [Figure 1a]. The unloaded microspheres [Figure 1b] showed two melting peaks $\left(62.7^{\circ} \mathrm{C}\right.$ and $\left.78.2^{\circ} \mathrm{C}\right)$ with corresponding enthalpies of $-4.216 \mathrm{~mW} / \mathrm{mg}$ and $-4.131 \mathrm{~mW} / \mathrm{mg}$. The DSC thermograms of insulin-loaded microspheres showed different melting peaks and thermal properties, as depicted in Figures 1c-e. The results showed that with the exemption of batch $\mathrm{U}_{1}$, which has a melting peak of $63.6^{\circ} \mathrm{C}$ with a corresponding enthalpy of $-4.131 \mathrm{~mW} / \mathrm{mg}$, all the drug-loaded microspheres showed two melting peaks $\left[64.2^{\circ} \mathrm{C}\right.$ and $85.6^{\circ} \mathrm{C}\left(\right.$ batch $\left.\mathrm{U}_{2}\right), 63.9^{\circ} \mathrm{C}$ and $81.6^{\circ} \mathrm{C}\left(\right.$ batch $\left.\mathrm{U}_{3}\right)$ ] with corresponding enthalpies of $-8.821 \mathrm{~mW} / \mathrm{mg}$ and $-7.662 \mathrm{~mW} / \mathrm{mg}$ (batch $\mathrm{U}_{2}$ ), $-3.360 \mathrm{~mW} / \mathrm{mg}$ and $-2.561 \mathrm{~mW} / \mathrm{mg}\left(\right.$ batch $\mathrm{U}_{3}$ ). The results of the DSC analysis showed that insulin was properly solubilized in the microspheres since higher melting point values indicated more ordered crystal structures in consistence with previous studies. ${ }^{[10,21-23]}$ Additionally, the physicochemical compatibility of the drug and the polymer studied by DSC suggested the absence of any incompatibility. The results revealed the compatibility of insulin and the polymer (Eudragit ${ }^{\circledR}$ RL 100). In addition, the formulations (drug-loaded microspheres) gave lower melting point values than insulin [Figure 1f], implying that insulin existed in an amorphous state in the formulations and was also properly solubilized in the microspheres. ${ }^{[2]}$

The drug-loading efficiency is shown in Table 2. The results indicate that there was no general pattern of drug entrapment with regard to increasing proportions of Eudragit ${ }^{\boxplus}$ RL100 used in preparing the microspheres. However, microspheres prepared with $3 \mathrm{~g}$ of Eudragit ${ }^{\circledR}$ RL100 entrapped a greater amount of insulin in comparison to the rest of the microspheres batches. The drug-loading efficiency is an important variable for assessing the drug-loading capacity of microspheres and their drug release profiles, thus suggesting the amount of drug that would be available at the site of absorption. This parameter is dependent on the process of preparation, physicochemical properties of the drug, and formulation variables ${ }^{[1]}$ It is also highly influenced by the type of polymer, polymer concentration, and solvent used to dissolve the drug and polymer. ${ }^{[2]}$ Microspheres formulated with $3 \mathrm{~g}$ of Eudragit ${ }^{\circledR}$ RL100 entrapped the highest amount of insulin compared with the rest of the formulations. 


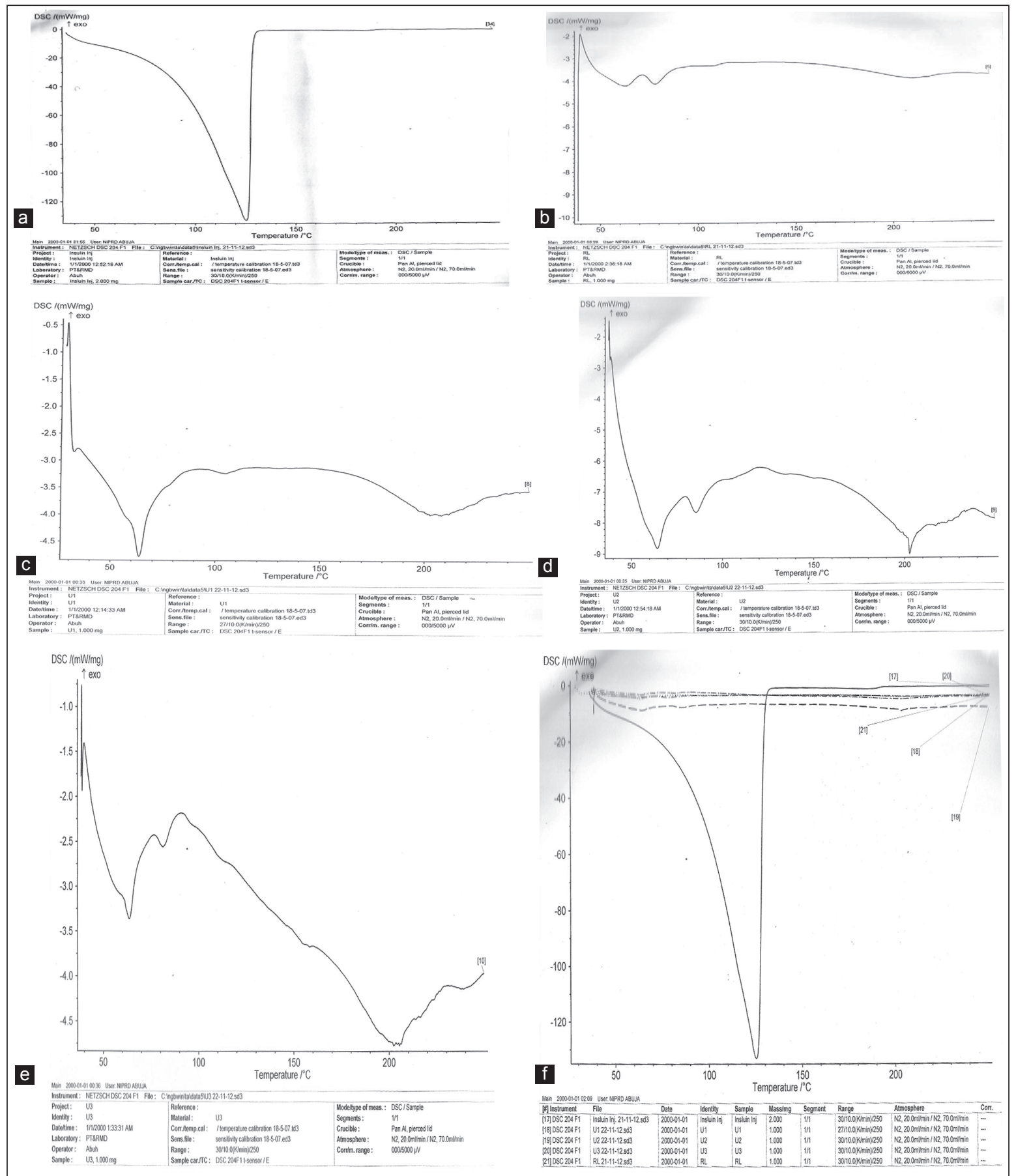

Figure 1: DSC thermogram of (a) Insulin (b) Unloaded Eudragit ${ }^{\circledR} R L 100$ microspheres (batch $U_{0}$ ) (c) Insulin-loaded microspheres batch $U_{1}\left(\right.$ d) Batch $U_{2}(e)$ Batch $U_{3}(f)$ Formulations overlayed $U_{1}, U_{2}$, and $U_{3}$ are insulin-loaded microspheres containing $2 \mathrm{~g}, 3$ $\mathrm{g}$, and $4 \mathrm{~g}$ of Eudragit ${ }^{\circledR} \mathrm{RL} 100$ while $\mathrm{U}_{0}$ is the unloaded microspheres

The particle size distribution of the microspheres is presented in Table 2. The mean particle size $(n=30)$ of insulin-loaded microspheres ranged from $14.20 \pm 0.30 \mu \mathrm{m}$ to $19.80 \pm 0.60 \mu \mathrm{m}$, whereas the mean particle size of unloaded microspheres batch was $13.50 \pm 0.90 \mu \mathrm{m}$. Thus, plain microspheres had the smallest mean particle size while insulin-loaded microspheres prepared with the highest amount of Eudragit ${ }^{\circledR}$ RL100 (300 mg) possessed the largest mean particle size. The photomicrographs of the microspheres are depicted in Figure 2. Generally, discrete, spherical, brownish, and free-flowing microspheres were obtained. The sizes of the microspheres were all within the micrometer range, indicating that the production process was able to achieve the intended end-point in consistence with previous reports. ${ }^{[1,2]}$ It would appear that the average size of the microspheres increased with an increase in the proportion of the polymer employed. This could be attributed to the fact that greater 
amounts of the polymeric materials formed thicker coatings around the drug particles leading to increased average size of the microspheres. The particle size of microspheres is an important parameter since it affects drug release and pharmacokinetics. [7] For microspheres engineered for parenteral administration, large particles would find it difficult to pass through the syringe. However, the microspheres evaluated in this study are intended for oral administration and the particle size influences only the rate of drug release and subsequent pharmacokinetics.

The results of the mucoadhesion of the microspheres to coweverted intestinal tissue as evaluated in simulated intestinal fluid (SIF) are presented in Table 2. It is evident from the table that the microspheres formulated showed good mucoadhesive properties and exhibited percentage mucoadhesion as high as $75.0 \%$ for unloaded microspheres and between $60.29 \%$ and $80.0 \%$ for insulin-loaded microspheres. The mucoadhesive property of unloaded microspheres was comparable to that of drugloaded microspheres. Although there was no particular order of mucoadhesiveness with respect to the proportion of polymer employed in the study, the order of the mucoadhesiveness of the microspheres batches is: $\mathrm{U}_{2}>\mathrm{U}_{0}>\mathrm{U}_{1}>\mathrm{U}_{3}$. Thus, batch $\mathrm{U}_{2}$ prepared with $300 \mathrm{mg}$ of Eudragit ${ }^{\circledR} \mathrm{RL} 100$ had the highest percentage mucoadhesion. The high percentage mucoadhesion of the different batches of the microspheres in SIF signifies high mucoadhesive property in intestinal conditions where insulin absorption takes place. ${ }^{[59-61]}$ This shows that the insulin-loaded microspheres will have a prolonged release and thereby enhance the bioavailability of insulin. The mucoadhesive results indicate that the microspheres may be preferable as carriers for drugs such as insulin targeted to have drug residence time in the small intestine. By implication, the microspheres' formulations may be a novel oral controlled drug delivery system for the delivery of insulin to the intestine owing to its high mucoadhesiveness in SIF.

Table 2 shows the values for bulk and tapped densities, Hausner qoutient and Carr compressibility indices for the various batches of the microspheres. The bulk and tapped densities of the formulations had values less than $1 \mathrm{~g} / \mathrm{mL}$ and while Carr's

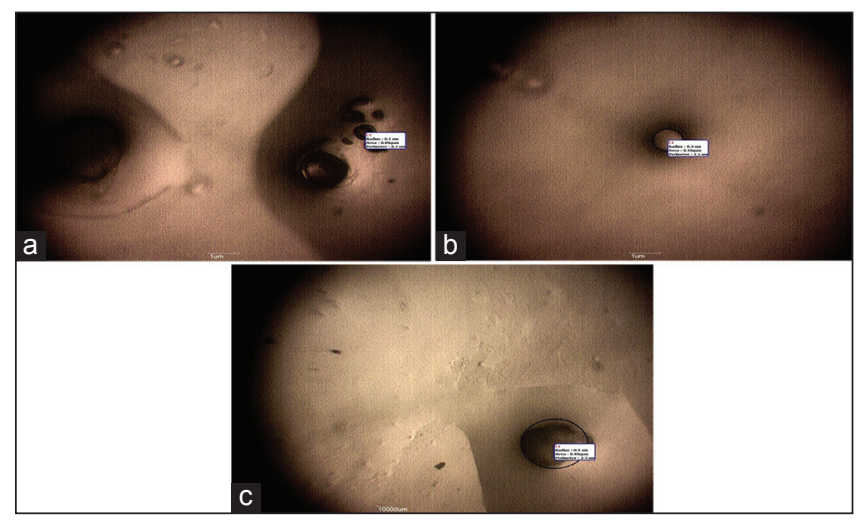

Figure 2: Photomicrograph of insulin-loaded microspheres containing various amounts of Eudragit ${ }^{\circledR} \mathrm{RL} 100$ (batch $\mathrm{U}_{0}$ ) (a) $2 \mathrm{~g}$ (batch $\mathrm{U}_{1}$ ) (b) $3 \mathrm{~g}\left(\right.$ batch $\mathrm{U}_{2}$ ) (c) $4 \mathrm{~g}$ (batch $\left.\mathrm{U}_{3}\right) \mathrm{U}_{1}, \mathrm{U}_{2}$ and $\mathrm{U}_{3}$ are insulin-loaded microspheres containing $2 \mathrm{~g}, 3 \mathrm{~g}$, and $4 \mathrm{~g}$ of Eudragit ${ }^{\circledR} \mathrm{RL} 100$ index values ranged from $13.43 \pm 1.63 \%$ to $18.91 \pm 1.54 \%$, Hausner's quotient ranged from $1.04 \pm 0.07$ to $1.24 \pm 0.03$. The consideration of the particle properties of microspheres intended for application is of critical importance. This is because important processes such as mixing, flow, and compression are procedures that are dependent on particle properties. ${ }^{[30,35]}$ The Hausner's quotient and Carr's compressibility index are some of the fundamental parameters from which certain important powder properties, especially flow can be predicted. These parameters are primarily dependent on the particle size distribution, shape of the particles, and tendency of the particles to adhere to one another. Hausner quotient values less than 1.25 have been reported to indicate good flow characteristics for powder. ${ }^{[22,23]}$ The HQ values obtained for the microspheres (1.04-1.24) indicate that the microspheres generally exhibit variations in the flowability of the various batches of the microspheres. Theoretically, the less compressible a material, the more flowable it would be. A Carr index value of $5-15 \%$ is indicative of excellent flow, 12$16 \%$ is good flow, and $18-21 \%$ is fair flow. ${ }^{[26-28]}$ Thus, it could be evaluated from the values obtained from the compressibility index of insulin-loaded Eudragit ${ }^{\circledR}$ entrapped microspheres $\left(\mathrm{U}_{1}=\right.$ $13.43 \pm 1.63 ; \mathrm{U}_{2}=22.23 \pm 2.08 ;$ and $\left.\mathrm{U}_{3}=18.91 \pm 1.54 \%\right)$ that there were varying flow patterns by the various batches of the microspheres. The results showed inconsistency in the flow behavior of the individual batches with respect to increasing proportions of Eudragit ${ }^{\circledR}$ RL 100 used in formulating the microspheres. This is because while insulin-loaded microspheres prepared with $2 \mathrm{~g}$ of Eudragit ${ }^{\circledR}$ RL 100 exhibited good flow, insulin-loaded microspheres formulated with Eudragit ${ }^{\circledR}$ RL 100 had fair flow and those based on $3 \mathrm{~g}$ of Eudragit ${ }^{\circledR}$ RL 100 showed poor flow behavior. The bulk and tapped densities showed good densification behavior of the microspheres. They also have a direct relationship with the flow characteristics and are a function of the particle size, particle size distribution, and particle shape. The polydispersity of the microspheres, which increases densification would improve the flowability of the microspheres.

The release profiles (in acidic and basic media) of insulin from the various insulin-loaded microspheres prepared from Eudragit ${ }^{\circledR} \mathrm{RL}$ 100 and filled into gelatin capsules are presented in Figure 3. The preparations exhibited a lag time before the onset of insulin release from the capsulated microspheres. Although there was rapid wetting of the gelatin capsule shell containing the insulin-loaded microspheres in the fluid environment, a total disintegration of the gelatin capsules shells was generally prolonged. The release profiles of insulin from the capsules [Figure 3] indicate that insulin release from the formulations commenced within 30 min in the dissolution media. Batch $\mathrm{U}_{1}$ microspheres gave the maximum release of $73.4 \%$ while batch $\mathrm{U}_{2}$ gave the least $(66.2 \%)$ and batch $\mathrm{U}_{3}$ released $71.3 \%$ of insulin at $3 \mathrm{~h}$ in basic medium. The insulin-loaded microspheres prepared with various amounts of Eudragit ${ }^{\circledR}$ RL 100 were filled into hard gelatin capsules such that each capsule shell contained an amount of insulin equivalent to 100 IU of soluble insulin. Each hard gelatin capsule was placed in a dissolution basket, which was held in place in the dissolution fluid with a clamp and stand. Sink condition was 
maintained throughout the experiment. The release medium was changed from acidic $(\mathrm{pH} 2.2)$ to basic $(\mathrm{pH} 7.2)$ to simulate the $\mathrm{pH}$ environment of the gastrointestinal tract (GIT) to aid the prediction of the release profile of the various formulations of the drug in the stomach and in the small intestine. ${ }^{[2,34,62]}$ The amounts of insulin released from the capsules were quantified. The preparations exhibited a lag time before the onset of insulin release from the capsulated microspheres. Although there was rapid wetting of the gelatin capsule shell containing the insulinloaded microspheres in the acidic environment of the stomach, total disintegration of the gelatin capsule shells occurred in the basic medium and was generally prolonged. This could have been due to the interaction of the polymeric matrix with the gelatin capsule shell that retarded further permeation of fluid through the capsule shell. This may contribute to the prolonged release of insulin from the microspheres. The fact that insulin release from the formulations commenced within $30 \mathrm{~min}$ in the dissolution media indicates that release of insulin started after fluid penetration of the gelatin capsule shell. It is quite improbable for insulin absorption to occur in the stomach. $[9,10,13,14,46,48,49,53,63]$ Thus, the amount of insulin released in the acidic medium $(\mathrm{pH}=2.2)$ was rather infinitesimal compared to the amount of insulin released in the basic medium $(\mathrm{pH}=7.2)$ where insulin absorption is expected to occur. Overall, the in vitro release profiles of insulin in the intestinal fluid ( $\mathrm{pH} 7.2)$ was high, indicating a significant release of insulin from all batches of the microspheres as shown in Figure 3. The drug concentration and the carrier are some of the main factors affecting drug release. ${ }^{[33]}$ Drug release from microspheres should theoretically be slower as the concentration of polymer is increased because of an increase in the path length through which the drug has to diffuse. However, the results obtained indicate that increase in the polymer (Eudragit ${ }^{\circledR}$ RL 100) concentration caused a slight decrease and thereafter an increase in the drug release rate from the microspheres formulations. Furthermore, a characteristic feature of the release profile of insulin from batch $\mathrm{U}_{1}$ of microspheres in the basic medium is the biphasic pattern of release unlike the slow and

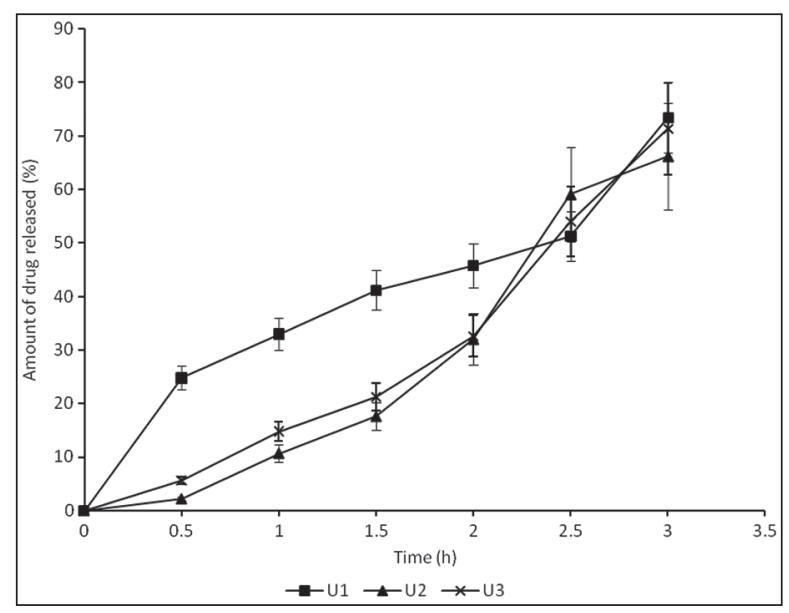

Figure 3: Drug release profiles of insulin from the microspheres in acidic $(\mathrm{pH}=2.2)$ and basic $(\mathrm{pH}=7.2)$ media $\mathrm{U}_{1}, \mathrm{U}_{2}$, and $\mathrm{U}_{3}$ are insulinloaded microspheres containing $2 \mathrm{~g}, 3 \mathrm{~g}$, and $4 \mathrm{~g}$ of Eudragit ${ }^{\circledR} \mathrm{RL} 100$ more sustained release obtained with batches $\mathrm{U}_{2}$ and $\mathrm{U}_{3}$. The rapid release of insulin, especially from the batch $\mathrm{U}_{1}$ in the first $30 \mathrm{~min}$ is possibly due to a burst effect caused by the leaching out of the unentrapped drug adhering to the surface of the microspheres after the initial rapid hydration and swelling. Burst release resulting in biphasic release pattern may be utilized in the therapeutic design of dosage forms. This has been observed in microspheres prepared using Eudragit ${ }^{\circledR}$ RL 100 polymer. ${ }^{[26,27,34]}$ There is a lot of peripheral attachment of the drug as a result of expulsion during microspheres drying (elastic contraction as seen in gels) or drug migration as a result of solvent drag during drying. In other words, the amounts of insulin released as a result of burst effect may likely represent the amounts that adhered weakly to the surface of the formulated microspheres. The remaining amounts, which were released in a more gradual pattern most likely represented the amounts that were entrapped into the core (matrix) of the microspheres. This may be an advantage because it would lead to a high initial blood concentration of the drug and a gradual release of the remaining drug. The microspheres had the tendency to fully sustain the release of insulin, as had been demonstrated for insulin microspheres in previous studies. ${ }^{[21,24,60]}$ The high and rapid release of insulin from the microspheres in the basic medium ( $\mathrm{pH}=7.2$ ), in addition to the burst effect, might also have been the result of the high rate of hydration of the microspheres in the basic medium, which, in turn, could be attributable to the properties of the polymer (Eudragit ${ }^{\circledR}$ RL 100) used in preparing the microspheres. The subsequent slow release phase could be a consequence of the decreasing residual amount of drug in the microspheres and the build-up of drug concentration in the dissolution medium in the course of time. This indicates that once the drug adhering to the microspheric surface has been leached, the drug release becomes diffusioncontrolled. ${ }^{[57]}$ Moreover, Eudragit ${ }^{\circledR}$ RL 100 possesses bioadhesive properties. ${ }^{[24,32,34]}$ This is an added advantage since the transit time of the dosage form would be prolonged in the small intestine for maximum absorption of the active ingredient.

Different mathematical models were used to describe the kinetics of insulin release from the microspheres. The criterion for selecting the most appropriate model was chosen on the basis of goodness of fit test. The result is presented in Table 4. A comparative evaluation of the $\left(r^{2}\right)$ values for the microspheres shows that all the formulae exhibited the highest regression coefficient when the percentage of the drug released was plotted against the square root of time. The results of the kinetic analysis of the in vitro release of insulin from the prepared microspheres revealed that in all cases, various batches

\begin{tabular}{|c|c|c|c|c|}
\hline Batch code & $\begin{array}{l}\text { Zero- } \\
\text { order }\end{array}$ & $\begin{array}{l}\text { First- } \\
\text { order }\end{array}$ & $\begin{array}{c}\text { Higuchi } \\
\text { square root }\end{array}$ & $\begin{array}{l}\text { Hixson- } \\
\text { Crowel }\end{array}$ \\
\hline $\mathrm{U}_{1}$ & 0.882 & 0.818 & 0.993 & 0.997 \\
\hline $\begin{array}{l}U_{2} \\
U_{3}\end{array}$ & $\begin{array}{l}0.767 \\
0.894 \\
\end{array}$ & $\begin{array}{l}0.867 \\
0.918 \\
\end{array}$ & $\begin{array}{l}0.989 \\
0.994 \\
\end{array}$ & $\begin{array}{l}0.988 \\
0.991 \\
\end{array}$ \\
\hline
\end{tabular}


of the formulation predominantly followed both the Higuchi and the Hixson-Crowell models of release. This indicates that the drug encapsulated in the polymer matrix was disorientated when in contact with polymer solution and this allowed the drug to diffuse out of the hydrated polymer matrix. This shows that a diffusioncontrolled release mechanism had occurred. These results conform to previous reports. ${ }^{[1,2,7]}$ Although the matrix was not soluble in water, the ability to hydrate in the medium paved way for the drug to diffuse due to structural disorientation that led to the formation of pores through which the drug is eventually released in a controlled manner. Differences in the ratios of the polymer used in the formulation accounted for the variation in the kinetics results obtained.

\section{CONCLUSION}

In this study, it was our aim to use Eudragit ${ }^{\circledR}$ RL 100 (pHindependent polymer) and magnesium stearate (a hydrophobic droplet stabilizer) in combination to improve the controlled release effect of insulin-loaded Eudragit ${ }^{\circledR}$-entrapped microspheres prepared by the emulsification-coacervation technique. Mucoadhesive insulin-loaded microspheres containing magnesium stearate and varying proportions of Eudragit ${ }^{\circledR}$ RL 100 were prepared by the emulsification-coacervation technique and evaluated for thermal properties, physicochemical performance, and in vitro dissolution in acidic and subsequently basic media. The results obtained indicate that stable, spherical, brownish, discrete, freeflowing and mucoadhesive insulin-loaded microspheres with size range of $14.20 \pm 0.30-19.80 \pm 0.60 \mu \mathrm{m}$ and loading efficiency of $74.55 \pm 1.05-75.90 \pm 1.94 \%$ were successfully formulated by the emulsification-coacervation technique using Eudragit ${ }^{\circledR}$ RL100. After 3 h, microspheres prepared with insulin - Eudragit ${ }^{\circledR}$ RL 100 ratios of $1: 4,1: 6$, and $1: 8$ released $73.40 \pm 1.38,66.20 \pm 1.59$, and $71.30 \pm 1.27(\%)$ of insulin, respectively. The results obtained from our studies demonstrated the effectiveness of the formulations as a carrier system for oral insulin delivery. This indicates that oral delivery of insulin is indeed possible using Eudragit ${ }^{\circledR}$ RL100 entrapped microspheres.

\section{Acknowledgements}

The authors wish to thank Evonik Industry, UK, for the generous gift of Eudragit ${ }^{\circledR}$ RL100 used in the study.

\section{Financial support and sponsorship}

Nil.

\section{Conflicts of interest}

There are no conflicts of interest.

\section{REFERENCES}

1. Zhang Y, Wei W, Lv P, Wang L, Ma G. Preparation and evaluation of alginate-chitosan microspheres for oral delivery of insulin. Eur J Pharm Biopharm 2011;77:11-9.

2. Timmy SA, Victor SP, Sharma CP, Valsala KJ. Betacyclodextrin complexed insulin loaded alginate microspheres - oral delivery system. Trends Biomater Artif Organs 2002;15:48-53.
3. Celek A, Celebi N, Tirnaksiz F, Tay A. A lecithin-based microemulsion of rh-insulin with aproprotin for oral administration: Investigation of hypoglycaemic effects in non-diabetic and STZinduced diabetic rats. Int J Pharm 2005;298:176-85.

4. Eaimtrakarn S, Rama Prasad YV, Ohno T, Konishi T, Yoshikawa Y, Shibata N, et al. Absorption enhancing effect of labrasol on the intestinal absorption of insulin in rats. J Drug Target 2002;10:255-60.

5. Kumria R, Goomber G. Emerging trends in insulin delivery: Buccal route. J Diabetol 2011;2:1-9.

6. Morishita M, Peppas NA. Is the oral route possible for peptide and protein drug delivery? Drug Discov Today 2006;11:905-10.

7. Pan Y, Zheng JM, Zhao HY, Li YJ, Xu H, Wei G. Relationship between drug effects and particle size of insulin-loaded bioadhesive microspheres. Acta Pharmacol Sin 2002;23: 1051-6.

8. Heinemann L, Pfutzner A, Heise T. Alternative routes of administration as an approach to improve insulin therapy: Update on dermal, oral, nasal and pulmonary insulin delivery. Curr Pharm Des 2001;7:1327-51.

9. Nakamura K, Murray RJ, Joseph JI, Peppas NA, Morishita M, Lowman AM. Oral insulin delivery using $P(M A A-g-E G)$ hydrogels: Effects of network morphology on insulin delivery characteristics. J Control Release 2004;95:589-99.

10. Sajeesh S, Sharma CP. Cyclodextrin-insulin complex encapsulated polymethacrylic acid based nanoparticles for oral insulin delivery. Int J Pharm 2006;325:147-54.

11. Akhter DT, Nijhu RS. Diabetes mellitus: A journey of insulin. Int Curr Pharm J 2012;1:32-42.

12. Evans M, Schumm-Draeger PM, Vora J, King AB. A review of modern insulin analogue pharmacokinetic and pharmacodynamic profiles in type 2 diabetes: Improvements and limitations. Diabet Obes Metab 2011;13:677-84.

13. Sarciaux JM, Acar L, Sado PA. Using microemulsion formulations for oral drug delivery of therapeutic peptides. Int $\mathrm{J}$ Pharm 1995;120:127-36.

14. Iwanaga KS, Ono S, Naroika K, Morimoto K, Kakemi M, Yamashita $S$, et al. Oral delivery of insulin by using surface coating liposomes: Improvement of insulin in GI tract. Int J Pharm 1997;157:73-80.

15. Chung H, Kim J, Um JY, Kwon IC, Jeong SY. Self-assembled "nanocubicle" as a carrier for peroral insulin delivery. Diabetologia 2004;45:448-51.

16. Dorkoosh FA, Coos Verhoef $\mathrm{J}$, Ambagts $\mathrm{MH}$, Rafiee-Tehrani $\mathrm{M}$, Borchard G, Junginger HE. Peroral delivery systems based on superporous hydrogel polymers: Release characteristics for the peptide drugs buserelin, octreotide and insulin. Eur J Pharm Sci 2002;15:433-9.

17. Cefalu WT. Evolving strategies for insulin delivery and therapy. Drugs 2004;64:1149-61.

18. Owens DR. New horizons - alternative routes for insulin therapy. Nat Rev Drug Discov 2002;1:529-40.

19. Nilkumhang $S$, Basit AW. The robustness and flexibility of an emulsion solvent evaporation method to prepare $\mathrm{pH}$-responsive microparticles. Int J Pharm 2009;377:135-41.

20. Singh MN, Hemant KS, Ram M, Shivakumar HG Microencapsulation: A promising technique for controlled drug delivery. Res Pharm Sci 2010;5:65-77.

21. Builders FP, Kunle OO, Adikwu MU. Preparation and characterization of mucinated agarose: A mucin-agarose physical crosslink. Int J Pharm 2008;356:174-80.

22. Builders FP, Ibekwe N, Okpako LC, Attama AA, Kunle OO. Preparation and characterization of mucinated cellulose microparticles for therapeutic and drug delivery purposes. Eur $\mathrm{J}$ Pharm Biopharm 2009;72:34-41. 
23. Builders PF, Kunle OO, Okpaku LC, Builders MI, Attama AA, Adikwu MU. Preparation and evaluation of mucinated sodium alginate microparticles for oral delivery of insulin. Eur J Pharm Biopharm 2008;70:777-83.

24. Jain D, Panda AK, Majumdar DK. Eudragit S100 entrapped insulin microspheres for oral delivery. AAPS Pharm Sci Tech 2005;6:E100-7.

25. Lamprecht $A$, Koenig $P$, Ubrich $N$, Maincent $P$, Neumann D. Low molecular weight heparin nanoparticles: Mucoadhesion and behaviour in Caco-2 cells. Nanotechnol 2006;17:3673-80.

26. Vaghani SS, Jivani NP, Vasanti S, Satish CS, Patel MM. Preparation and characterization of 5-FU loaded microspheres of Eudragit ${ }^{\circledR}$ and ethylcellulose. Acta Pharm Sci 2010;52:391-9.

27. Paharia A, Yadar AK, Rai G, Jain SK, Pacholi SS, Agrawal GP. Eudragit-coated pectin microspheres of 5-fluorouracil for colon targeting. AAPS PharmSciTech 2007;8:12.

28. Jain A, Teja MN, Pariyani L, Balamuralidhara V, Gupta NV. Formulation and evaluation of spray-dried esomeprazole magnesium microspheres. Trop J Pharm Res 2013;12:299-304.

29. Son YJ, Yoo HS. pH-responsive microspheres encapsulated with iron oxide nanoaggregates for gastrointestinal delivery. J Bioact Compat Polym 2012;27:54-66.

30. Bhalerao SS, Lalla JK, Rane MS. Study of processing parameters influencing the properties of diltiazem hydrochloride microspheres. J Microencapsul 2001;18:299-307.

31. Lamprecht A, Yamamoto H, Takeuchi H, Kawashima Y. Design of $\mathrm{pH}$-sensitive microspheres for the colonic delivery of the immunosuppressive drug tacrolimus. Eur J Pharm Biopharm 2004;58:37-43.

32. Okada $\mathrm{H}$, Toguchi $\mathrm{H}$. Biodegradable microspheres in drug delivery. Crit Rev Ther Drug Carrier Syst 1995;12:1-99.

33. Deore KL, Thombre NA, Gide PS. Formulation and development of tinidazole microspheres for colon targeted drug delivery system. J Pharm Res 2013;5:158-65.

34. Haznedar S, Dortunç B. Preparation and in vitro evaluation of Eudragit microspheres containing acetazolamde. Int J Pharm 2004;269:131-40.

35. Hogan JE. Film-coating materials and their properties. In: Cole G, editor. Pharmaceutical Coating Technology. Special ed.New York: Informa Healthcare; 2008. p. 7-19.

36. Pamnani D. Reality check on oral insulin. Pharm Expr 2008;3:16-31.

37. Rosa GD, Iommeli R, La Rotonda MI, Mitro A, Quaglia F. Influence of the co-encapsulation of different non-ionic surfactants on the properties of PLGA insulin-loaded microspheres. J Control Release 2000;69:283-95.

38. Singh S, Patel D, Patel NR, Kumar K, Gautam MK. Insulin oral delivery may be possible. Int J Pharm Prof Res 2010;1:46-51.

39. Whitehead K, Shen $Z$, Mitragotri S. Oral delivery of macromolecules using intestinal patches: Applications for insulin delivery. J Control Release 2004;98:37-45.

40. Zhang Y, Wu X, Meng L, Zhang Y, Ai R, Qi N, et al. Thiolated Eudragit nanoparticles for oral insulin delivery: Preparation, characterization and in vivo evaluation. Int $\mathrm{J}$ Pharm 2012;436:341-50.

41. Tuesca A, Lowman A. The Oral Delivery of Insulin Using Protein Conjugates in Complexation Hydrogels. Poster Presentation, Biomaterials and Drug Delivery Laboratory. Philadelphia, Pennsylvania, USA: Drexel University; 2006.

42. Caliceti $P$, Veronese EM. Improvement of the physicochemical and biopharmaceutical properties of insulin by poly (ethylene glycol) conjugation. S T P Pharm Sci 1999;9:107-13.

43. Cui FD, Shi K, Zhang L, Tao A, Kawashima Y. Biodegradable nanoparticles loaded with insulin-phospholipid complex for oral delivery: Preparation, in vitro characterization and in vivo evaluation. J Control Release 2006;114:242-50.

44. Cui FD, Tao AJ, Cun DM, Zhang LQ, Shi K. Preparation of insulinloaded PLGA-Hp55 nanoparticles for oral delivery. J Pharm Sci 2007;96:421-7.

45. Damgé C, Hillaire-Buys D, Peuche R, Hoeltzel A, Micheal C, Ribes G. Effect of orally administered insulin nanocapsules in normal and diabetic dogs. Diab Nutr Metab 1995;8:3-9.

46. Damge $C$, Maincent $P$, Ubrich $N$. Oral delivery of insulin associated to polymeric nanoparticles in diabetic rats. J Contro Release 2007;117:163-70.

47. Kavimandan NJ, Losi E, Wilson JJ, Brodbelt JS, Peppas NA Synthesis and characterization of insulin-transferrin conjugates. Bioconjug Chem 2006;17:1376-84.

48. Krauland $A H$, Guggi $D$, Bernkop-Schnürch A. Oral insulin delivery: The potential of thiolated chitosan-insulin tablets on non-diabetic rats. J Control Release 2004;95:547-55.

49. Lin $\mathrm{YH}$, Mi FL, Chen CT, Chang WC, Peng SF, Liang HF, et al. Preparation and characterization of nanoparticles shelled with chitosan for oral insulin delivery. Biomacromolecules 2007;8:146-52.

50. Shima M, Tanaka M, Fujii T, Egawa K, Kimura Y, Adachi S, et al. Oral administration of insulin included in fine W/O/W emulsions to rats. Food Hydrocoll 2006;20:523-31.

51. Morishita M, Matsuzawa A, Takayama K, Isowa K, Nagai T. Improving insulin enteral absorption using water-in-oil-in-water emulsion. Int JPharm 1998;172:189-98.

52. Liu R, Huang SS, Wan YH, Ma GH, Su ZG. Preparation of insulin-loaded PLA/PLGA microcapsules by a novel membrane emulsification method and its release in vitro. Colloids Surf $B$ Biointerfaces 2006;51:30-8.

53. Li CL, Deng YJ. Oil-based formulations for oral delivery of insulin. J Pharm Pharmacol 2004;56:1101-7.

54. Toorisaka E, Hashida M, Kamiya N, Ono H, Kokazu Y, Goto M. An enteric-coated dry emulsion formulation for oral insulin delivery. J Control Release 2005;107:91-6.

55. Cárdenas-Bailón F, Osorio-Revilla G, Gallardo-Velázquez T. Microencapsulation techniques to develop formulations of insulin for oral delivery: A review. J Microencapsul 2013;30:409-24.

56. Yüksel N, Baykara T. Preparation of polymeric microspheres by the solvent evaporation method using sucrose stearate as a droplet stabilizer. J Microencapsul 1997;14:725-33.

57. Ofokansi KC, Adikwu MU. Formulation and evaluation of microspheres based on gelatin-mucin admixtures for the rectal delivery of cefuroxime sodium. Trop J Pharm Res 2007;6: 825-32.

58. Kim B, Peppas NA. In vitro release behavior and stability of insulin in complexation hydrogels as oral drug delivery carriers. Int J Pharm 2003;266:29-37.

59. Kinesh VP, Neelam DP, Punit BP, Bhavesh SB, Pragna KS. Novel approahces for oral delivery of insulin and current status of ora insulin products. Int J Pharm Sci Nanotechnol 2010;3:1057-64.

60. Marias E, Hamman J, Plessis Ld, Lemmer R, Steenekamp J. Eudragit $^{\circledR}$ L100/N-trimethylchitosan chloride microspheres for oral insulin delivery. Molecules 2013;18:6734-47.

61. Gowthamarajan K, Kulkami GT. Oral insulin - fact or fiction Resonance 2003;55:38-43.

62. Freitas S, Merkle HP, Gander B. Microencapsulation by solvent extraction/evaporation: Reviewing the state of the art of microsphere preparation process technology. J Control Release 2005;102:313-32.

63. Chandler SG, Thomas NW, Ilum L. Nasal absorption in the rat III. Effect of orally lysophospholipids on insulin absorption and nasal histology. Pharm Res 1994;11:1623-30. 